\title{
Serological diagnosis of amoebiasis by immunofluorescence
}

\author{
SOMNATE BOONPUCKNAVIG AND R. C. NAIRN \\ From the Department of Pathology, Monash University, Melbourne
}

SYNOPSIS A positive serological diagnosis of amoebiasis could be made by immunofluorescence in 66 of 78 established cases, taking a serum titre of 16 or higher as diagnostic: at this level there were no false positives among 94 control sera. The test is simple and may be carried out on amoebic smears stored for several months in 2-octanol. The serological activity is largely confined to the IgG immunoglobulin fraction and is specific for Entamoeba histolytica; cross reactions were not detected with other protozoa. Gel diffusion serological analysis permitted a positive diagnosis of amoebiasis in 60 of the 78 cases, and, combining this with the immunofluorescence test, raised the diagnostic score to 71 cases.

Following Goldman's (1953) immunofluorescence demonstration of specific antibody in rabbits immunized with Entamoeba histolytica, antibody titration by similar means in human subjects with amoebiasis has now been reported (Goldman, 1966; Jeanes, 1966). The following study is an account of serum antibody titration in a number of human cases of amoebiasis and unaffected control subjects providing the basis for a simple standardized immunofluorescence diagnostic test.

\section{METHODS}

SERA These were obtained from 78 patients with acute or chronic dysentery or hepatic amoebiasis or symptomless cyst passing from Thailand, South Africa, and South America. The diagnosis had been confirmed by clinical evidence and conventional laboratory investigations. Control sera totalling 94 included 10 from patients with other parasitic infestation, 12 each respectively from patients with ulcerative colitis, intestinal malabsorption, pernicious anaemia, connective tissue diseases with positive antinuclear factor, dysglobulinaemias, miscellaneous non-gastrointestinal illnesses, and from normal individuals.

IMMUNOFLUORESCENCE A virulent strain of E. histolytica, isolated in 1961 at the School of Public Health and Tropical Medicine, University of Sydney, was maintained in Bacto Endamoeba Medium (Difco Laboratories) with $10 \%$ horse serum and subcultured every second day. Smears of amoebae were prepared by centrifuging 48hour-old cultures and discarding the supernatant, then

Received for publication 21 April 1967 washing the sedimented organisms twice with phosphate-

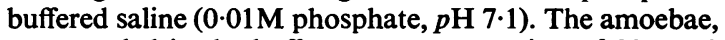
resuspended in the buffer at a concentration of 30 to 50 per c.mm., were dropped by Pasteur pipette onto a chemically clean slide, which received 4 separate drops each about $8 \mathrm{~mm}$. in diameter. The slides were dried on a warm plate at about $37^{\circ} \mathrm{C}$. and then placed for at least one minute in a slurry of isopentane-liquid nitrogen. After removal they were dried with a fan at $0-4^{\circ} \mathrm{C}$. for two hours and immersed in 2 -octanol at $-30^{\circ} \mathrm{C}$. for at least 15 minutes, again fan dried at $0-4^{\circ} \mathrm{C}$. for at least one hour, whereafter they were ready for staining (Maxwell, Ward, and Nairn, 1966). Alternatively they could be stored in the octanol at room temperature $\left(20-23^{\circ} \mathrm{C}\right.$.) or lower for up to four months for staining later; antigenicity was preserved for six months by such storage at $-30^{\circ} \mathrm{C}$.

Immunofluorescent staining was carried out by the sandwich method using goat antihuman globulin conjugated with fluorescein isothiocyanate with the same general procedures described elsewhere (Nairn, 1964). Serum was applied for 30 minutes in a damp chamber at room temperature to the four amoebic spots on the microscope slide as follows: (1) test serum; (2) known positive amoebiasis serum; (3) normal human serum; (4) nil. The slide was carefully rinsed with the buffered saline, avoiding any mixture between the drops of sera, and washed in buffer for two periods of five minutes. Excess of buffer was removed by draining and wiping the slide, care being taken to keep all four amoebic spots moist until the application for 30 minutes of the antihuman globulin conjugate, which had been previously absorbed with rat tissue homogenate to prevent nonspecific staining. The preparation was rinsed and washed with buffer as before, and counterstained by immersion in $0.1 \%$ Evans blue for five minutes and washing in 
buffer for 10 minutes. After brief air-drying at room temperature it was mounted in buffered glycerol for fluorescence microscopy.

All test sera were inactivated by heating to $56^{\circ} \mathrm{C}$. for 30 minutes. Titrations of possible positive sera by doubling dilutions with the buffered saline were carried out four to a slide by using the four-spot amoebic preparations. The highest dilution giving unambiguous fluorescent staining of the amoebae was taken as the end point. Results were recorded without prior knowledge of the clinical diagnosis.

Specificity of the immunofluorescent staining reaction was assessed from the comparisons of the amoebiasis and control sera, from the results of absorption of amoebiasis sera by $E$. histolytica and Amoeba proteus, and from attempts at staining microscopical preparations of other protozoa. For the absorptions, sera were incubated with equal volumes of methanol-fixed protozoal sediments obtained by washing in buffered saline and centrifuging at about $10,000 \mathrm{~g}$ for 15 minutes; one absorption was carried out at $37^{\circ} \mathrm{C}$. for one hour and a second overnight at $0-4^{\circ} \mathrm{C}$., the serum being recovered between and after absorptions by recentrifuging. The microscopical preparations of other protozoa were prepared in the same way as parallel $E$. histolytica smears. Staining was carried out directly in a few experiments with a labelled high titre amoebiasis serum, which was also used in 'blocking' tests.

Twelve representative amoebiasis sera were examined to determine the class of immunoglobulin responsible for the specific immunofluorescent staining. For this purpose, smears were treated in the usual way with the first layer of test serum and then with labelled monospecific antihuman globulin with activity respectively against IgM, IgG, and $\operatorname{IgA}$.

GEL DIFFUSION Sera were also tested by immunodiffusion in agar gels on microscope slides (Mansi, 1958) against amoebic antigen and concomitant clostridium antigen prepared by the method of Maddison, Powell, and Elsdon-Dew (1965). Recording of precipitin lines was made after 48 hours' diffusion at room temperature.

\section{RESULTS}

Of the 78 amoebiasis sera, 66 gave an immunofluorescent staining titre of 16 or more, whereas none of the 94 control sera reached this level (Table I). The highest titre in the amoebiasis sera was 512 (three cases) and the lowest less than 4 (four cases, including three of dysentery and one of symptomless cyst passer). In contrast, the highest titre in the control sera was 8 (three cases diagnosed respectively as ulcerative colitis, lobar pneumonia, and systemic lupus erythematosus) and the lowest less than 4 (66 cases). Thus a titre of 16 or more might reasonably be regarded as diagnostic of amoebiasis, a titre of 8 as suggestive of the disease, and a titre less than 4 as suggestive of its absence. The only obvious correlation between the clinical
TABLE I

IMMUNOFLUORESCENCE TITRES IN AMOEBIASIS AND CONTROL SERA

\begin{tabular}{|c|c|c|}
\hline Immunofluorescence Titre & Amoebiasis Sera (78) & Control Sera (94) \\
\hline 512 & 3 & 0 \\
\hline 256 & 8 & 0 \\
\hline 128 & 9 & 0 \\
\hline 64 & 22 & 0 \\
\hline 32 & 22 & 0 \\
\hline 16 & 2 & 0 \\
\hline 8 & 4 & 3 \\
\hline 4 & 4 & 25 \\
\hline$<4$ & 4 & 66 \\
\hline
\end{tabular}

type of amoebiasis and the immunofluorescence titre (Table II) was that the highest values 256 and 512 were found in 10 out of 33 sera from patientso with hepatic involvement whilst only one out of $45 \mathrm{~J}$ intestinal cases had a titre as high as 256 .

\section{TABLE II}

TITRE OF KNOWN AMOEBIASIS SERA RELATED TO CLINICAL TYPE OF DISEASE

$\begin{array}{llll}\text { Immunofiuorescence } & \text { Hepatic } & \text { Acute } & \text { Chronic } \\ \text { Titre } & \text { Amoebiasis } & \text { Dysentery } & \begin{array}{l}\text { Dysenteryor } \\ \text { Cyst Passing }\end{array}\end{array}$

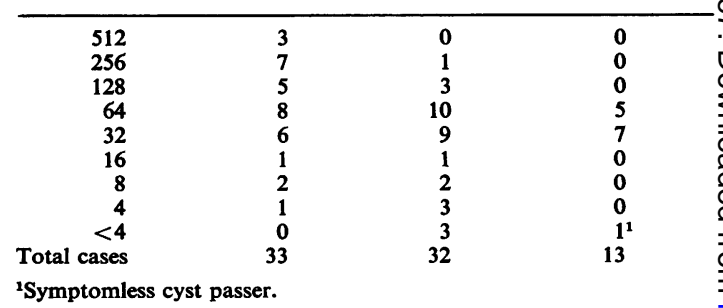

'Symptomless cyst passer.

The immunofluorescent staining of $E$. histolytica (Fig. 1) was shown to be specific by the negativen staining results obtained with the control sera, and:the marked reduction in staining which occurred 3 when the amoebiasis sera has been absorbed by $E$. histolytica. There was no diminution of staining after serum absorption with Amoeba proteus oro Tetrahymena or rat liver homogenate. Amoebiasis? sera did not stain other protozoa including $E$. coli, , E. invadens, Endolimax nana, Amoebae proteus, Trichomonas vaginalis, and Tetrahymena. Directo staining with the labelled amoebiasis serum couldn be blocked by prior application to the microscopical N preparation of the unconjugated serum.

Examination of the 12 representative amoebiasis sera for the presence of reacting antibodies of the IgG, IgM, and IgA immunoglobulin classes revealed $ळ$ IgG antibody in all sera and a trace of IgM in three cases (two of six hepatic amoebiasis and one of two chronic dysentery sera tested).

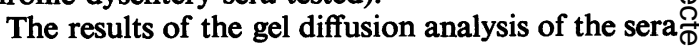
are summarized in Table III which shows that 60 을 


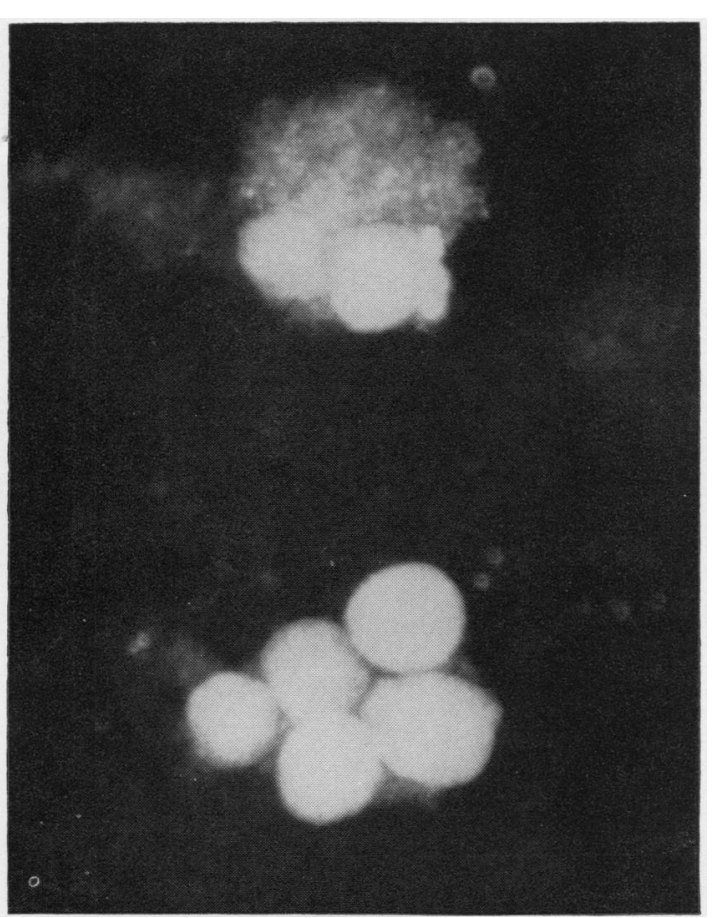

FIG. 1. Immunofluorescent staining of Entamoeba histolytica smear by amoebiasis serum and fluorescein-labelled antihuman globulin. Counterstaining of background debris by Evans blue $(\times 630)$.

of the 78 amoebiasis sera gave precipitin lines. The proportion of positive results was highest in the hepatic amoebiasis sera ( 31 of the 33 cases). None of the 22 control sera gave any precipitation.

TABLE III

GEL DIFFUSION PRECIPITATION BY AMOEBIASIS AND CONTROL SERA

\begin{tabular}{lcc} 
& $\begin{array}{l}\text { No. of Sera } \\
\text { Examined }\end{array}$ & $\begin{array}{l}\text { No. with } \\
\text { Precipitins }\end{array}$ \\
\hline Hepatic amoebiasis & 33 & 31 \\
Acute dysentery & 32 & 21 \\
Chronic dysentery or cyst passer & 13 & 8 \\
Representative control sera & 22 & 0
\end{tabular}

Examination by gel diffusion of the eight amoebiasis sera with low immunofluorescent staining titres of 4 or 8 disclosed that precipitin lines were produced by three of the five acute dysentery cases and by two of the three hepatic amoebiasis cases. The four sera with a negative immunofluorescence titre were also negative by gel diffusion. Sera numbering 18 in all gave negative gel diffusion results and of these 11 had immunofluorescence titres of 16 or higher: the titre was 32 in six of the sera and 64 in four. Only seven of the 78 amoebiasis sera were undiagnosed by either test: four of these were completely negative, two sera had an immunofluorescence titre of 4 , and one serum a titre of 8 .

\section{DISCUSSION}

If facilities are available for immunofluorescence, the present test for serum antibody to E. histolytica can be recommended for routine diagnostic work. The method described of preparing and storing amoebic smears reduces non-specific staining and also avoids the labour of preparing fresh preparations every time a new serum is to be tested. Octanolstorage for four months or more still permits satisfactory staining, and smears in octanol can be transmitted by post so that a central supply system could obviate any need for peripheral laboratories themselves to cultivate amoebae. Given the amoebic smears, the test is just as simply performed and interpreted as that for antinuclear factor which is now a routine procedure in many laboratories.

The technique suggested for routine use is to screen test sera at a 1:4 dilution, always including in each series simultaneous examination of the reaction of a known positive and negative serum at the same dilution and of the conjugate alone. Any test sera observed to stain the amoebae are then titrated by doubling dilutions. Use of the Evans blue counterstain, by providing a reddish fluorescent background, facilitates the reading of the titration end point. It is economical and probably quite sufficient for diagnostic purposes to limit the serum titration to four dilutions, $1: 8$ to $1: 64$ on a single four-spot slide.

Taking an immunofluorescence titre of 16 as diagnostic of amoebiasis, $85 \%$ of the cases were detected without false positives among the control sera. The gel diffusion test had a detection rate of $77 \%$ and the two tests combined raised the diagnostic score to $91 \%$. The immunofluorescence test is preferred because the antigen is more simply prepared, is not required fresh every time and results are obtainable more quickly, but where facilities for both tests exist they are usefully complementary.

Confidence in the immunofluorescence test is enhanced by the finding that the anti-amoebic activity in patients' sera is almost exclusively in the IgG fraction and is specific for E. histolytica without cross reaction with other amoebic strains. Negative reactions with the immunofluorescence test included the only symptomless cyst passer in the series and not unexpectedly relatively more acute dysentery cases than either chronic dysentery or hepatic amoebiasis. We have insufficient clinical information to be able 
to offer any explanation of the single case of hepatic amoebiasis found to be negative both by the immunofluorescence and gel diffusion tests.

We wish to thank Dr. S. J. Powell and Miss R. G. Hodgson, Amoebiasis Research Unit, Institute of Parasitology, Durban, for amoebiasis and control sera for blind trial of our test and also for smears of different amoebic species for specificity control. We also thank Dr. M. Restrepo and Dr. D. Botero, University of Antioquia, Columbia, Dr. T. Savanat, Bangkok School of Tropical Medicine, Dr. R. I. Sommerville, University of Adelaide, and Dr. J. R. L. Forsyth, Department of Microbiology, Monash University, for various sera and amoebic preparations. The work was supported by a grant from the National Health and Medical Research Council while S. B. of the Faculty of Tropical Medicine, Bangkok University of Medical Science, was in receipt of a Colombo Plan fellowship award.

\section{REFERENCES}

Goldman, M. (1953). Amer. J. Hyg., 5, 319.

(1966). Amer. J. trop. Med. Hyg., 15, 694.

Jeanes, A. L. (1966). Brit. med. J., 1, 1464.

Maddison, S. E., Powell, S. J., and Elsdon-Dew, R. (1965). Amer. J. trop. Med. Hyg., 14, 554.

Mansi, W. (1958). Nature (Lond.), 181, 1289.

Maxwell, A., Ward, H. A., and Nairn, R. C. (1966). Stain Technol., 41, 305.

Nairn, R. C. (1964). Fluorescent Protein Tracing, 2nd. ed. Livingstone, Edinburgh. 